\title{
Musculoskeletal disease in MDA5-related type I interferonopathy - a Mendelian mimic of Jaccoud's arthropathy
}

DOI:

10.1002/art.40179

\section{Document Version}

Accepted author manuscript

Link to publication record in Manchester Research Explorer

\section{Citation for published version (APA):}

Martins de Carvalho, L., Ngoumou, G., Park, J. W., Ehmke, N., Deigendesch, N., Kitabayashi, N., Melki, I., Souza, F. F. L., Tzschach, A., Nogueira-Barbosa, M. H., Ferriani, V., Louzada-Junior, P., Marques Junior, W., Lourenco, C. M., Horn, D., Kallinich, T., Stenzel, W., Hur, S., Rice, G., \& Crow, Y. (2017). Musculoskeletal disease in MDA5related type I interferonopathy - a Mendelian mimic of Jaccoud's arthropathy. Arthritis \& Rheumatology (Hoboken) . https://doi.org/10.1002/art.40179

\section{Published in:}

Arthritis \& Rheumatology (Hoboken)

\section{Citing this paper}

Please note that where the full-text provided on Manchester Research Explorer is the Author Accepted Manuscript or Proof version this may differ from the final Published version. If citing, it is advised that you check and use the publisher's definitive version.

\section{General rights}

Copyright and moral rights for the publications made accessible in the Research Explorer are retained by the authors and/or other copyright owners and it is a condition of accessing publications that users recognise and abide by the legal requirements associated with these rights.

\section{Takedown policy}

If you believe that this document breaches copyright please refer to the University of Manchester's Takedown Procedures [http://man.ac.uk/04Y6Bo] or contact uml.scholarlycommunications@manchester.ac.uk providing relevant details, so we can investigate your claim.

\section{OPEN ACCESS}




\section{Musculoskeletal disease in MDA5-related type I interferonopathy - a Mendelian mimic of Jaccoud's arthropathy}

Luciana Martins de Carvalho, MD, PhD ${ }^{1 *}$; Gonza Ngoumou, MD ${ }^{2 *}$; Ji Woo Park ${ }^{3 \star}$; Nadja Ehmke, $\mathrm{MD}^{4^{*}}$; Nikolaus Deigendesch, MD, $\mathrm{PhD}^{5}$; Naoki Kitabayashi, BSc ${ }^{6,7}$; Isabelle Melki, MD ${ }^{6,7}$; Flávio Falcäo L Souza, MD; Andreas Tzschach, MD; Marcello H Nogueira-Barbosa, MD, $\mathrm{PhD}^{10}$; Virgínia Ferriani, MD, PhD ${ }^{1}$; Paulo Louzada-Junior, $\mathrm{MD}, \mathrm{PhD}^{8}$; Wilson Marques Junior, $\mathrm{MD}, \mathrm{PhD}^{11}$; Charles $\mathrm{M}$ Lourenço, $\mathrm{MD}, \mathrm{PhD}^{11}$; Prof Denise Horn, $\mathrm{MD}^{4}$; Tilmann Kallinich, $\mathrm{MD}^{2}$; Werner Stenzel, MD ${ }^{5}$; Sun Hur, PhD ${ }^{12}$; Gillian I Rice, PhD $^{13}$; Yanick J Crow, MD, PhD ${ }^{6,7,13,14}$

* These authors contributed equally

${ }^{1}$ Pediatric Rheumatology Division, Ribeirao Preto Medical School, University of São Paulo, Brazil

${ }^{2}$ Department of Pediatric Pneumology and Immunology and Center for Chronically Sick Children of the Charité - Charité University Medecine Berlin, Berlin, Germany ${ }^{3}$ Biology Department in Morrissey College of Arts and Sciences, Boston College, Chestnut Hill, USA

${ }^{4}$ Institute of Medical and Human Genetics, Charité - Universitätsmedizin Berlin; Berlin Institute of Health (BIH), Berlin, Germany

${ }^{5}$ Department of Neuropathology, Charité - Universitätsmedizin, Berlin, Germany ${ }^{6}$ INSERM UMR 1163, Laboratory of Neurogenetics and Neuroinflammation, Paris, France

${ }^{7}$ Paris Descartes University, Sorbonne-Paris-Cité, Institut Imagine, Paris, France

This article has been accepted for publication and undergone full peer review but has not been through the copyediting, typesetting, pagination and proofreading process which may lead to differences between this version and the Version of Record. Please cite this article as an 'Accepted Article', doi: 10.1002/art.40179 (C) 2017 American College of Rheumatology

Received: Mar 16, 2017; Revised: May 15, 2017; Accepted: J un 08, 2017 
MDA5 Jaccoud

${ }^{8}$ Rheumatology Division, Ribeirao Preto Medical School, University of São Paulo, Brazil

${ }^{9}$ Institute of Clinical Genetics, Technische Universität Dresden, Dresden, Germany

${ }^{10}$ Internal Medicine Department, Radiology Division, Ribeirao Preto Medical School,

University of São Paulo, Brazil

${ }^{11}$ Neurosciences and Behavioural Sciences, Ribeirao Preto Medical School, University of São Paulo, Brazil

${ }^{12}$ Biological Chemistry and Molecular Pharmacology, Harvard Medical School, Boston, USA

${ }^{13}$ Division of Evolution and Genomic Sciences, School of Biological Sciences, Faculty of Biology, Medicine and Health, University of Manchester, Manchester Academic Health Science Centre, Manchester, UK

${ }^{14}$ Département de Génétique, Hôpital Necker Enfants Malades, Assistance PubliqueHôpitaux de Paris, Paris, France

Corresponding author: Yanick J Crow. Institut Imagine, Laboratory of Neurogenetics and Neuroinflammation, 24 boulevard du Montparnasse. Paris, 75015, France. yanickcrow@mac.com

\section{Financial support}

N.E. is a participant in the BIH-Charite Clinical Scientist Program funded by the Charité - Universitätsmedizin Berlin and the Berlin Institute of Health. YJC acknowledges funding from the European Research Council (GA 309449: Fellowship to Y.J.C) and a state subsidy managed by the National Research Agency (France) under the "Investments for the Future" (ANR-10-IAHU-01). 
MDA5 Jaccoud

The authors have not received financial support or other benefits from commercial sources for the work reported on in the manuscript, or any other financial reward / incentive creating a potential conflict of interest or the appearance of a conflict of interest with regard to the work here.

(1)

\section{Abbreviations}

AGS: Aicardi-Goutières syndrome

CRP: C-reactive protein

ESR: Erythrocyte sedimentation rate

JA: Jaccoud's arthropathy

JIA: Juvenile idiopathic arthritis

SLE: Systemic lupus erythematosus

SMS: Singleton-Merten syndrome

TNF: Tumour necrosis factor 
MDA5 Jaccoud

\section{Abstract}

\section{Objectives}

To define the molecular basis of a multisystem phenotype with progressive musculoskeletal disease of the hands and feet including camptodactyly, subluxation and tendon rupture reminiscent of Jaccoud's arthropathy.

\section{Methods}

We ascertained two families segregating an autosomal dominant phenotype encompassing musculoskeletal disease and variable additional features including psoriasis, dental abnormalities, cardiac valve involvement, glaucoma and basal ganglia calcification. We measured the expression of interferon-stimulated genes in peripheral blood and skin, and undertook targeted Sanger sequencing of the IFIH1 gene encoding the cytosolic double-stranded RNA sensor MDA5. We also assessed the functional consequences of IFIH1 gene variants using an in vitro interferon beta reporter assay in HEK293 cells.

\section{Results}

We recorded an upregulation of type I interferon-induced gene transcripts in all five patients tested, and identified a heterozygous gain-of-function mutation in IFIH1 in each family resulting in different substitutions of the threonine residue at position 331 of MDA5. Both of these variants were associated with increased interferon beta 
MDA5 Jaccoud

expression in the absence of exogenous dsRNA ligand, consistent with constitutive activation of MDA5.

\section{Conclusions}

These cases highlight the significant musculoskeletal involvement that can be associated with mutations in MDA5, and emphasize the value of testing for an upregulation of interferon signalling as a marker of the underlying molecular lesion. Our data both indicate that Singleton-Merten syndrome and neuroinflammation described in the context of MDA5 gain-of-function constitute part of the same type I interferonopathy disease spectrum, and provide possible novel insight into the pathology of Jaccoud's arthropathy. 
MDA5 Jaccoud

The type I interferonopathies represent discrete examples of a disturbance of the homeostatic control of type I interferon signalling due to Mendelian mutations, where a constitutive upregulation of type I interferon activity is considered directly relevant to pathogenesis. Definition of the type I interferonopathies has emphasized involvement of the central nervous system and the skin as primary clinical characteristics (1). More recently, the observation of mutations in IFIH1, encoding the cytosolic double-stranded RNA (dsRNA) sensor MDA5, has highlighted the possibility of joint disease in this context also $(2,3)$. Here we describe two families segregating autosomal dominant mutations in MDA5 where musculoskeletal involvement demonstrating overlap with Jaccoud's arthropathy (JA) was a major clinical feature. We also provide a brief overview of joint disease so far described in the broader type I interferonopathy grouping, the recognition of which may become of increasing importance as anti-interferon therapies are developed.

Methods

\section{Study participants}

Clinical and molecular data were ascertained through direct clinical contact. Written informed consent was obtained from participating family members. The study was approved by the Comité de Protection des Personnes (ID-RCB / EUDRACT: 2014A01017-40) and the Leeds (East) Research Ethics Committee (reference number 10/H1307/132).

\section{Interferon score}


MDA5 Jaccoud

This method has been described in detail elsewhere (4). Whole blood was collected into PAXgene tubes, total RNA extracted using a PreAnalytix RNA isolation kit and RNA concentration assessed by spectrophotometry (FLUOstar Omega, Labtech). Quantitative reverse transcription polymerase chain reaction (qPCR) analysis was performed using the TaqMan Universal PCR Master Mix (Applied Biosystems), and CDNA derived from $40 \mathrm{ng}$ total RNA. Using TaqMan probes for IFI27 (Hs01086370_m1), IFI44L (Hs00199115_m1), IFIT1 (Hs00356631_g1), ISG15 (Hs00192713_m1), RSAD2 (Hs01057264_m1), and SIGLEC1 (Hs00988063_m1), the relative abundance of each target transcript was normalized to the expression levels of HPRT1 (Hs03929096_g1) and 18S (Hs999999001_s1), and assessed with the Applied Biosystems StepOne Software v2.1 and DataAssist Software v.3.01. For each of the 6 probes, individual data were expressed relative to a single calibrator. $R Q$ (relative quantification) is equal to $2^{-\Delta \Delta C t}$ i.e. the normalized fold change relative to the control data. The median fold change of the 6 genes compared to the median of 29 previously collected healthy controls is used to create an interferon score for each individual, with an abnormal interferon score being defined as greater than +2 standard deviations above the mean of the control group i.e. 2.466.

\section{Mutational analysis}

Primers were designed to amplify the coding exons of IFIH1 (sequences available on request). Purified PCR amplification products were sequenced using BigDye ${ }^{\mathrm{TM}}$ terminator chemistry and an $\mathrm{ABI} 3130$ DNA sequencer. Mutation description is based on the reference cDNA sequence NM_022168, with nucleotide numbering 
MDA5 Jaccoud

beginning from the first $A$ in the initiating ATG codon. Variants were assessed using the in silico programmes SIFT (http://sift.jcvi.org) and Polyphen2 (http://genetics.bwh.harvard.edu/pph2/), and population allele frequencies obtained from the ExAC (http://exac.broadinstitute.org) database.

\section{Interferon reporter assay}

The pFLAG-CMV4 plasmid encoding IFIH1 was described elsewhere [5]. Indicated mutations were introduced using KAPA HiFi DNA polymerase. HEK293T cells (ATCC) were maintained in 48-well plates in Dulbecco's modified Eagle medium (Cellgro) supplemented with $10 \%$ heat-inactivated fetal calf serum and $1 \%$ Lglutamine. At $\sim 80 \%$ confluence, cells were co-transfected with pFLAG-CMV4 plasmids encoding wild-type or mutant IFIH1 (10 ng, unless mentioned otherwise), interferon beta (IFN-b) promoter driven firefly luciferase reporter plasmid (100 ng) and a constitutively expressed Renilla luciferase reporter plasmid ( $p R L-C M V, 10 \mathrm{ng}$ ) by using lipofectamine2000 (Life) according to the manufacturer's protocol. The medium was changed 6 hours post-transfection, and cells were subsequently stimulated with poly(l:C) $(0.5 \mu \mathrm{g} / \mathrm{ml}$, Invivogen $)$ or in vitro transcribed $162 \mathrm{bp}$ dsRNA $(0.5 \mathrm{ug} / \mathrm{ml})$ using lipofectamine2000. Cells were lysed 16 hours post-stimulation and IFN $\beta$ promoter activity was measured using the Dual Luciferase Reporter assay (Promega) and a Synergy2 plate reader (BioTek). Firefly luciferase activity was normalized against Renilla luciferase activity. Error bars represent the standard deviation of three independent experiments.

\section{Histopathology}


MDA5 Jaccoud

Snap frozen skin samples from F1972_P2, and a control without any obvious rheumatic or inflammatory skin disease, were obtained by open biopsy. $7 \mu \mathrm{m}$ cryostat sections were stained by $\mathrm{H} \& \mathrm{E}$ and by immunohistochemistry with the following antibodies: ISG15 (Abcam, Cambridge, UK, clone ab14374, 1:50), SIGLEC1 (Novus biologicals, Abingdon, UK, clone HSn7D2), CD45, (DAKO, Glostrup Denmark, clone 2B11) and CD3 (DAKO, rabbit polyclonal). Staining was performed using the iview-Ventana DAB (diaminobenzidine)-Detection Kit (Ventana, Tucson, Arizona, 85755 USA). Appropriate biotinylated secondary antibodies were used, and visualization of the reaction product was carried out on a Benchmark XT immunostainer (Ventana, Tucson, Arizona, 85755 USA).

\section{Results}

(a)

\section{Family 1938 (F1938)}

F1938_P1: The proband is an 18 year old female born to non-consanguineous parents of Brazilian ancestry. She was delivered at 32 weeks gestation by caesarean section indicated because of placental abruption. A gluteal fistula, diagnosed at age two months, necessitated multiple surgical interventions between the ages of two and seven years. She sat at five months of age (adjusted for gestation at birth), and walked independently at age 24 months. At four years of age muscle weakness and difficulties with climbing stairs were noted. Electromyography was suggestive of a myopathic process, and a muscle biopsy showed striated muscle fibres with discrete 
MDA5 Jaccoud

irregularity of myofibril diameter and peripheral nuclei in a subsarcolemmal distribution. Creatine kinase tested on multiple occasions was consistently normal.

Beginning at the age of two years she reported joint pain, and subsequently developed progressive deformities of the hands and feet. Rheumatologic review at seven years of age revealed significant deformities of both feet, and limitation of movement of the cervical spine, elbows, wrists, hands, knees and ankles (Figure $1 \mathrm{~A}$ - F). There was no obvious muscle weakness at this time. She was noted to have dry skin, multiple lentigines and hypochromic macular lesions (Figure 1E). She was given a diagnosis of juvenile idiopathic arthritis (JIA) and started on methotrexate and, subsequently, the tumour necrosis factor (TNF) alpha inhibitor Etanercept. At age 12 years, considering the degree of joint damage and poor response to Etanercept, a putative diagnosis of psoriatic arthritis was made and treatment initiated with Infliximab, but which was stopped after seven months following an infusion reaction. Due to pain at the injection site, a subsequent course of Adalimumab was also stopped. After the appearance of diffuse cutaneous guttate psoriatic lesions at age 13 years, she was tried again on Etanercept in combination with Leflunomide, with equivocal therapeutic benefit. Erythrocyte sedimentation rate (ESR) and C-reactive protein (CRP) have been consistently normal, and autoantibodies have always been negative.

In addition, this female was noted to have experienced delayed eruption of her first and secondary dentition. During adolescence she was found to be hypertensive, and echocardiography revealed concentric left ventricle hypertrophy, left atrial dilation 
MDA5 Jaccoud

and aortic root dilation with aortic valve insufficiency. There was no evidence of aortic calcification.

At the age of 18 years her height is $146 \mathrm{~cm}$ (- 2 SD below the mean). There is no evidence of glaucoma. Dense calcification of the basal ganglia was observed on cranial CT imaging (Figure 1G) in the absence of overt neurological features.

F1938_P2: The proband's mother was initially evaluated at 35 years of age because of a deforming polyarthritis of the hands and feet. Joint involvement was reported to have started at six years of age. She lost almost all of her teeth during adolescence and early adulthood, necessitating the use of a dental prosthesis. She received a diagnosis of psoriatic arthropathy and was started on methotrexate and the TNF alpha inhibitor Infliximab at age 44 years, with apparently limited efficacy.

Currently, aged 45 years, she has a height of $145 \mathrm{~cm}$ (-3 SD below the mean), dry skin and lentigines. There is subluxation, camptodactyly and ulnar deviation in the hands, with plantar arch collapse, valgus deformity and bilateral plantar callosities of the feet (Figure 2A - D, F - G). There is also reduction of the range of motion at the elbows, and valgus orientation of the knees. Radiological evaluation demonstrated acro-osteolysis, joint subluxation and tendon insertion calcification. Imaging of her jaw confirmed complete loss of her teeth (Figure 2E). She was found to be hypertensive, and echocardiography revealed left ventricular hypertrophy with moderate aortic insufficiency and aortic stenosis. Calcification of the aortic valve was observed on chest CT (Figure $2 \mathrm{H}$ ), and calcification of the basal ganglia seen on cranial CT in the absence of neurological signs. 
MDA5 Jaccoud

F1938_P3: A maternal aunt to the proband was evaluated at age 27 years, with a height of $144 \mathrm{~cm}$ (-3 SD below the mean). She reported the loss of almost all of her teeth during adolescence, necessitating the use of a dental prosthesis from the age of 15 years. There was a history of arthralgia of the wrists, metacarpophalangeal and interphalangeal joints, elbows, knees and ankles, with progressive deformation starting at age three years. Radiographs revealed diffuse osteopenia, acro-osteolysis and calcifications at tendon insertions and of the plantar fascia. She had a six year history of guttate psoriasis. Chest CT demonstrated calcification of the aortic valve, and calcification of the basal ganglia was observed on cranial CT in the absence of overt neurological disease.

In the family history, a maternal uncle was evaluated at 24 years of age with a history of a deforming arthropathy beginning at age 12 years. He demonstrated features of acro-osteolysis of the hands with metacarpophalangeal subluxations. There were scaly erythematous plaques involving the trunk, scalp, limbs and buttocks. Lesional biopsy was compatible with psoriasis vulgaris with hyperkeratosis and accumulation of neutrophils in the corneal layer, acanthosis with scarce granulosa layer and mild spongiosis associated with micro-abscesses. He was treated with methotrexate with good response of the cutaneous features, but with no apparent effect on his joint disease. He was subsequently lost to follow-up. It was reported that the proband's maternal grandmother and a further maternal aunt also demonstrated a deforming arthropathy, cutaneous lesions and cardiac valvopathy from which they both died. The aunt had two children, also described to have a 
MDA5 Jaccoud

severe arthropathy. None of these individuals were available for clinical or molecular evaluation.

\section{Family 1972 (F1972)}

F1972_P1: The proband is a female child currently aged nine years born to nonconsanguineous parents of Caucasian ancestry. She presented to the rheumatology service at age eight years with muscle weakness and pain in her legs. At this time her height was $125 \mathrm{~cm}$ (median for age). She was noted to have short distal phalanges of the hands and feet, and hallux valgus deformity of both feet. X-rays showed wide medullary cavities of the metacarpals and the proximal phalanges of the hands (Figure 3A), and acro-osteolysis of the distal phalanges of the feet. There were no skin abnormalities, ophthalmologic examination identified no evidence of glaucoma and there was no calcification of the aorta or cardiac valves. Her developmental history was normal. She reported a delayed eruption of the secondary dentition, having lost her first tooth at age eight years. Laboratory findings showed normal levels of antinuclear antibodies. ESR and CRP were consistently normal. Antibodies against double-stranded DNA were elevated (30.8 U/ml; normal < 20), and expression of CD169/Siglec1 on monocytes was increased (5).

F1972_P2: This 47 year old male is the father of the proband. He reported a history of joint pain without evidence of arthritis beginning at age 20 years. He experienced delayed tooth eruption, and the early loss of secondary dentition with resorption of the dental roots. Glaucoma was diagnosed at the age of 11 years, and psoriasis as a young adult. There was a history of rupture of both quadriceps tendons at age 34 
MDA5 Jaccoud

and 35 years. Currently he demonstrates multiple lentigines with hypochromic macules, and deformations of the hands and feet with acro-osteolysis of the phalanges and osteopenia seen on X-ray (Figure 3B - E). Laboratory findings showed elevated rheumatoid factor and levels of antinuclear (1:2560), anti-SSA/anti-SS-Ro and anti-angiotensin II type 1 antibodies, whilst antibodies against double-stranded DNA were normal. Expression of CD169/Siglec1 on monocytes was increased. A lesional skin biopsy demonstrated ortho and parakeratosis with a markedly thickened epithelial layer and prominent dermal papillae (Supplementary Figure 1A, 1B). The epidermal layer showed strong immunoreactivity for ISG15 (Supplementary Figure 1C, 1D), and numerous Siglec-1 positive macrophages and dendritic cells (Supplementary Figure 1E, 1F) were seen in inflammatory subepidermal foci and epithelial infiltrates. There was a prominent CD45 ${ }^{+}$leukocytic infiltrate (Supplementary Figure 1G, 1H) composed of macrophages and $\mathrm{T}$ cells (Supplementary Figure 1G inset), whilst B cells were absent (not shown).

The paternal grandmother of the proband was reported to have experienced delayed tooth eruption and early loss of secondary dentition, as well as osteopenia, bilateral hallux valgus, thickening of the Achilles tendons and cervical myelopathy. Other family members were also reported with glaucoma, bone and dental abnormalities but no further details were available.

\section{Molecular data}

In family F1938 all three patients tested were heterozygous for a missense variant c.992C $>$ T / p.Thr331lle in IFIH1, whilst in F1972 the two patients sampled were 
MDA5 Jaccoud

heterozygous for a missense variant c.992C>G / p.Thr331Arg in the same gene (Figure 4). The threonine at position 331 is highly conserved to Baker's yeast (Supplementary Figure 2). Both substitutions are predicted to be damaging by in silico programs, and neither is annotated on the ExAC database. Mapping of the Thr331 residue onto the crystal structure of the 2CARD deletion construct ( $\triangle 2 \mathrm{CARD})$ demonstrated that the residue lies within the Hel1 domain, one of two highly conserved core helicase domains responsible for binding RNA and RNA-dependent ATP hydrolysis (Supplementary Figure 3).

\section{Interferon signature}

All five individuals tested from both families demonstrated a marked upregulation of interferon-induced gene transcripts, with interferon scores of 29.7, 15.1 and 16.8 (normal < 2.466) when tested at the ages of 18,45 and 27 years respectively in family F1938; and of 14.0 and 18.8 when tested at the ages of nine and 47 years respectively in family F1972 (Figure 5A).

\section{Interferon reporter assay}

Interferon beta (IFN-b) reporter stimulatory activity of wild-type and mutant MDA5 in HEK293T cells was also assessed (Figure 5B). HEK293T cells express low levels of endogenous viral RNA receptors, including IFIH1, as evidenced by low interferon production upon stimulation with dsRNA, allowing comparison of the signaling activity of ectopically expressed receptors. Wild-type MDA5 was only induced upon stimulation with poly I:C, a long (> $1 \mathrm{~kb})$ dsRNA, and not with short (162 bp) dsRNA, 
MDA5 Jaccoud

and activity was negligible in the absence of exogenous RNA. In contrast, as for previously described disease-associated mutations (6), basal levels of interferon signalling were markedly increased with the two p.Thr331 mutant constructs in the absence of exogenous RNA.

\section{0 \\ Discussion}

We describe five individuals from two families demonstrating progressive joint disease of the hands and feet consequent upon heterozygous gain-of-function mutations in MDA5. Musculoskeletal involvement began in infancy or early adulthood and was severely deforming in the four oldest patients ascertained. Contractures, subluxations, tendon rupture and tendon-insertion calcification were major features, becoming more prominent over time. Joint swelling, effusion and synovial thickening were absent clinically and on radiological imaging. In one patient, F1938_P1, the degree of joint involvement prompted a diagnosis of JIA and of psoriatic arthritis, leading to the use of TNF alpha antagonists with minimal efficacy. Her more severely affected mother, F1938_P2, was also treated with disease-modifying anti-rheumatic drugs, again to little effect. All five individuals experienced significant dental problems, with a variable defect of primary exfoliation and abnormal permanent dentition leading to premature tooth loss. Furthermore, three patients were diagnosed with psoriasis, two with cardiac valve calcification and one with glaucoma.

Singleton-Merten syndrome (SMS) is an autosomal dominant trait characterized by

bone disease particularly affecting the hands and feet, abnormal tooth development, and aortic and cardiac valve calcification associated with a considerable risk of 
MDA5 Jaccoud

mortality $(7,8)$. Additional features include glaucoma, psoriasis and poorly defined muscle weakness. A possibly characteristic facies with broad forehead has been reported in certain cases. In 2015, a p.Arg822GIn (c.2456G>A) heterozygous gainof-function mutation in MDA5 was identified to segregate with the SMS phenotype in two families comprising multiple affected individuals, and in an isolated patient where the mutation occurred de novo (2).

The two families described here conform to previous descriptions of SMS. However, their disease is not due to the recurrent p.Arg822GIn mutation identified by Rutsch et al. (2), indicating that SMS-like features are not exclusively associated with that particular amino acid substitution. In further support of this suggestion, Bursztejn et al. reported a 41 year old male with camptodactyly of the fifth fingers, bilateral hallux valgus and loss of permanent teeth after adolescence, whose disease was due to a p.Ala489Thr MDA5 substitution (3).

Gain-of-function mutations in MDA5 have also been described in a broad range of neuroimmunological phenotypes, encompassing the early-onset encephalopathy Aicardi-Goutières syndrome (AGS), isolated spastic paraparesis, and spastic paraparesis with systemic lupus erythematosus (SLE) (6, 9-12). Interestingly, all three members of F1938 demonstrated calcification of the basal ganglia, a cardinal sign of AGS, in the absence of any neurological features. Calcification of the basal ganglia and abnormalities of the white matter were also recorded in the adult male patient reported by Bursztejn et al. (3), again in the absence of overt neurological disease. These observations indicate that the SMS and neuroinflammatory phenotypes seen in the context of MDA5 gain-of-function constitute part of the same 
MDA5 Jaccoud

disease spectrum. Indeed, we note that Case 2 described by Singleton and Merten in 1973 developed a fever and lost the ability to walk at the age of 14 months, after a previously unremarkable neonatal period (8). Furthermore, and effectively conclusive of this point, Buers et al. very recently reported the previously described p.Arg822GIn SMS-associated mutation in a child with an AGS-like phenotype(13), whilst Pettersson et al. published a female with SLE and spastic paraparesis in association with the same mutation.

The type I interferonopathies represent a set of diseases grouped on the premise of a shared pathogenic role of upregulated type I interferon signalling. A recent review suggested that this grouping currently comprises 18 distinct genotypes including $I F I H 1$ (1). MDA5, encoded by IFIH1, recognizes viral RNA in the cytosol leading to the induction of a type I interferon-mediated immune response. All of the IFIH1 mutations so far characterized confer a gain of function on MDA5, resulting in constitutive activation of the receptor and enhanced type I interferon signalling. Consistent with published data in a large cohort of patients with MDA5 mutations (2, $3,14)$, all five affected individuals tested here demonstrated a marked upregulation of type I interferon signalling. As such, an interferon signature clearly represents a useful indicator of MDA5-related pathology.

The nature of the musculoskeletal disease associated with mutations in MDA5, and the role of type I interferon in this process, remains undefined. We note the frequent observation of psoriasis in the context of SMS (reference 8 and three patients reported here), and that variants in IFIH1 have been associated with an increased risk of psoriasis (15). We note also a lack of consistent autoantibody production in 
MDA5 Jaccoud

SMS $(2,7)$, the absence of raised inflammatory markers (ESR, CRP), and the limited therapeutic efficacy of anti-TNF alpha agents in two patients from F1938. Although bone changes have been described in SMS, in particular widened medullary cavities of the metacarpals and acro-osteolysis, joint spaces are well preserved without any obvious erosions or involvement of the epiphyses / metaphyses, and with no evidence of an increased fracture risk. Musculoskeletal disease seems mainly limited to the hands and the feet, with an absence of obvious joint swelling. Muscle weakness has been reported in a number of SMS patients in the literature, as for F1938_P1 here, but this is not a universal feature, and investigations do not support a specific neuromuscular disturbance or myositis.

JA has been described as a deforming arthropathy of the hands and the feet, seen most commonly in the context of SLE. Importantly, there is an absence of cartilage loss or erosion of juxta-articular bone on X-ray $(16,17)$. The pathogenesis of JA is unknown, but is thought to involve tendon inflammation, with work in an animal model suggesting a possible link with enhanced interferon signalling (18). Tendon rupture, as previously described in SMS (7) and as recorded in patient F1972_2 here, has been reported as a frequent co-occurrence with JA in SLE patients (19). Taking these features into account, we suggest that MDA5-related musculoskeletal disease might be considered as a Mendelian mimic of JA, providing possible clues to the underlying pathogenesis.

The prominent joint disease observed in the SMS phenotype indicates a particular association with mutations in IFIH1 compared to other type I interferonopathy genotypes (20). However, arthropathy has been noted in individual reports of 
MDA5 Jaccoud

patients with dysfunction of SAMHD1 (21-24), $\operatorname{TREX1}(25,26), \operatorname{STING}(27,28), \mathrm{RIG}-$ I (29) and PSMB8 (30)(Supplementary Table 1), possibly arguing for a shared underlying pathology related to enhanced type I interferon signalling. If this is proven to be the case, the identification of such interferon-associated phenotypes will be of increasing clinical relevance as anti-interferon treatments become available (31).

\section{Acknowledgements}

N.E. is a participant in the BIH-Charite Clinical Scientist Program funded by the Charité - Universitätsmedizin Berlin and the Berlin Institute of Health. YJC acknowledges funding from the European Research Council (GA 309449: Fellowship to Y.J.C) and a state subsidy managed by the National Research Agency (France) under the "Investments for the Future" (ANR-10-IAHU-01).

\section{References}

1. Rodero MP, Crow YJ. Type I interferon-mediated monogenic autoinflammation: The type I interferonopathies, a conceptual overview. J Exp Med. 2016;213(12):2527-38.

2. Rutsch F, MacDougall M, Lu C, Buers I, Mamaeva O, Nitschke Y, et al. A Specific IFIH1 Gain-of-Function Mutation Causes Singleton-Merten Syndrome. Am J Hum Genet. 2015;96(2):275-82.

3. Bursztejn AC, Briggs TA, del Toro Duany $\mathrm{Y}$, Anderson BH, O'Sullivan J, Williams SG, et al. Unusual cutaneous features associated with a heterozygous 
MDA5 Jaccoud

gain-of-function mutation in IFIH1: overlap between Aicardi-Goutieres and SingletonMerten syndromes. Br J Dermatol. 2015;173(6):1505-13.

4. Rice GI, Forte GM, Szynkiewicz M, Chase DS, Aeby A, Abdel-Hamid MS, et al. Assessment of interferon-related biomarkers in Aicardi-Goutieres syndrome associated with mutations in TREX1, RNASEH2A, RNASEH2B, RNASEH2C, SAMHD1, and ADAR: a case-control study. Lancet Neurol. 2013;12(12):1159-69.

5. Li Y, Lee PY, Kellner ES, Paulus M, Switanek J, Xu Y, et al. Monocyte surface expression of Fcgamma receptor RI (CD64), a biomarker reflecting type-I interferon levels in systemic lupus erythematosus. Arthritis research \& therapy. 2010;12(3):R90.

6. Rice GI, Del Toro Duany Y, Jenkinson EM, Forte GM, Anderson BH, Ariaudo G, et al. Gain-of-function mutations in IFIH1 cause a spectrum of human disease phenotypes associated with upregulated type I interferon signaling. Nat Genet. 2014;46(5):503-9.

7. Feigenbaum A, Muller C, Yale C, Kleinheinz J, Jezewski P, Kehl HG, et al. Singleton-Merten syndrome: an autosomal dominant disorder with variable expression. Am J Med Genet A. 2013;161A(2):360-70.

8. Singleton EB, Merten DF. An unusual syndrome of widened medullary cavities of the metacarpals and phalanges, aortic calcification and abnormal dentition. Pediatr Radiol. 1973;1(1):2-7.

9. Oda H, Nakagawa K, Abe J, Awaya T, Funabiki M, Hijikata A, et al. AicardiGoutieres syndrome is caused by IFIH1 mutations. Am J Hum Genet. 2014;95(1):121-5. 
MDA5 Jaccoud

10. Crow YJ, Zaki MS, Abdel-Hamid MS, Abdel-Salam G, Boespflug-Tanguy O, Cordeiro NJV, et al. Mutations in ADAR1, IFIH1, and RNASEH2B Presenting As Spastic Paraplegia. Neuropediatrics. 2014;45(6):386-U20.

11. Van Eyck L, De Somer L, Pombal D, Bornschein S, Frans G, Humblet-Baron S, et al. IFIH1 mutation causes systemic lupus erythematosus with selective IgAdeficiency. Arthritis \& rheumatology. 2015.

12. Pettersson M, Bergendal B, Norderyd J, Nilsson D, Anderlid BM, Nordgren A, et al. Further evidence for specific IFIH1 mutation as a cause of Singleton-Merten syndrome with phenotypic heterogeneity. Am J Med Genet A. 2017;173(5):1396-9.

13. Buers I, Rice GI, Crow YJ, Rutsch F. MDA5-Associated Neuroinflammation and the Singleton-Merten Syndrome: Two Faces of the Same Type I Interferonopathy Spectrum. J Interferon Cytokine Res. 2017;37(5):214-9.

14. Rice GI, Melki I, Fremond ML, Briggs TA, Rodero MP, Kitabayashi N, et al. Assessment of Type I Interferon Signaling in Pediatric Inflammatory Disease. J Clin Immunol. 2016:1-10.

15. Genetic Analysis of Psoriasis C, the Wellcome Trust Case Control C, Strange A, Capon F, Spencer CC, Knight J, et al. A genome-wide association study identifies new psoriasis susceptibility loci and an interaction between HLA-C and ERAP1. Nat Genet. 2010;42(11):985-90.

16. Santiago MB. Miscellaneous non-inflammatory musculoskeletal conditions. Jaccoud's arthropathy. Best Pract Res Clin Rheumatol. 2011;25(5):715-25.

17. Santiago MB. Jaccoud's arthropathy: proper classification criteria and treatment are still needed. Rheumatol Int. 2013;33(11):2953-4.

18. Mensah KA, Mathian A, Ma L, Xing L, Ritchlin CT, Schwarz EM. Mediation of nonerosive arthritis in a mouse model of lupus by interferon-alpha-stimulated 
MDA5 Jaccoud

monocyte differentiation that is nonpermissive of osteoclastogenesis. Arthritis Rheum. 2010;62(4):1127-37.

19. Alves EM, Macieira JC, Borba E, Chiuchetta FA, Santiago MB. Spontaneous tendon rupture in systemic lupus erythematosus: association with Jaccoud's arthropathy. Lupus. 2010;19(3):247-54.

20. Crow YJ, Chase DS, Lowenstein Schmidt J, Szynkiewicz M, Forte GM, Gornall HL, et al. Characterization of human disease phenotypes associated with mutations in TREX1, RNASEH2A, RNASEH2B, RNASEH2C, SAMHD1, ADAR, and IFIH1. Am J Med Genet A. 2015;167(2):296-312.

21. Dale RC, Gornall H, Singh-Grewal D, Alcausin M, Rice GI, Crow YJ. Familial Aicardi-Goutieres syndrome due to SAMHD1 mutations is associated with chronic arthropathy and contractures. Am J Med Genet A. 2010;152A(4):938-42.

22. Ramantani G, Kohlhase J, Hertzberg C, Innes AM, Engel K, Hunger S, et al. Expanding the phenotypic spectrum of lupus erythematosus in Aicardi-Goutieres syndrome. Arthritis Rheum. 2010;62(5):1469-77.

23. Xin B, Jones S, Puffenberger EG, Hinze C, Bright A, Tan $H$, et al. Homozygous mutation in SAMHD1 gene causes cerebral vasculopathy and early onset stroke. Proc Natl Acad Sci U S A. 2011;108(13):5372-7.

24. Yarbrough K, Danko C, Krol A, Zonana J, Leitenberger S. The importance of chilblains as a diagnostic clue for mild Aicardi-Goutieres syndrome. Am J Med Genet A. $2016 ; 170(12): 3308-12$.

25. Rice G, Newman WG, Dean J, Patrick T, Parmar R, Flintoff K, et al. Heterozygous mutations in TREX1 cause familial chilblain lupus and dominant Aicardi-Goutieres syndrome. Am J Hum Genet. 2007;80(4):811-5. 
MDA5 Jaccoud

26. Sugiura $\mathrm{K}$, Takeichi $\mathrm{T}$, Kono $\mathrm{M}$, Ito $\mathrm{Y}$, Ogawa $\mathrm{Y}$, Muro $\mathrm{Y}$, et al. Severe chilblain lupus is associated with heterozygous missense mutations of catalytic amino acids or their adjacent mutations in the exonuclease domains of 3'-repair exonuclease 1 . The Journal of investigative dermatology. 2012;132(12):2855-7.

27. Liu Y, Jesus AA, Marrero B, Yang D, Ramsey SE, Montealegre Sanchez GA, et al. Activated STING in a vascular and pulmonary syndrome. $\mathrm{N}$ Engl $\mathrm{J}$ Med. $2014 ; 371(6): 507-18$

28. Jeremiah N, Neven B, Gentili M, Callebaut I, Maschalidi S, Stolzenberg MC, et al. Inherited STING-activating mutation underlies a familial inflammatory syndrome with lupus-like manifestations. The Journal of clinical investigation. 2014;124(12):5516-20.

29. Jang MA, Kim EK, Now H, Nguyen NT, Kim WJ, Yoo JY, et al. Mutations in DDX58, which Encodes RIG-I, Cause Atypical Singleton-Merten Syndrome. Am J Hum Genet. 2015;96(2):266-74.

30. Garg A. Clinical review\#: Lipodystrophies: genetic and acquired body fat disorders. J Clin Endocrinol Metab. 2011;96(11):3313-25.

31. Fremond ML, Rodero MP, Jeremiah N, Belot A, Jeziorski E, Duffy D, et al. Efficacy of the Janus kinase $1 / 2$ inhibitor ruxolitinib in the treatment of vasculopathy associated with TMEM173-activating mutations in 3 children. The Journal of allergy and clinical immunology. 2016;138(6):1752-5. 
MDA5 Jaccoud

Table 1. Summary of the clinical and radiological features observed in MDA5 mutation positive patients from families F1938 and F1972.

\begin{tabular}{|c|c|c|c|c|c|}
\hline Case & F1938_P1 & F1938_P2 & F1938_P3 & F1972_P1 & F1972_P2 \\
\hline Mutation & c.992C>T / p.Thr331/le & c.992C>T / p.Thr331lle & c.992C>T / p.Thr331/le & c.992C>G / p.Thr331Arg & c.992C>G / p.Thr331Arg \\
\hline Gender & Female & Female & Female & Female & Male \\
\hline $\begin{array}{l}\text { Age at onset } \\
\text { (years) }\end{array}$ & Early infancy & 6 & 3 & 8 & 11 \\
\hline $\begin{array}{l}\text { Current age } \\
\text { (years) }\end{array}$ & 18 & 45 & 27 & 9 & 47 \\
\hline $\begin{array}{l}\text { Height at last } \\
\text { contact }(\mathrm{cm} / \\
\text { years / SD of } \\
\text { mean) }\end{array}$ & $146 / 18 /-2$ & $145 / 45 /-3$ & $144 / 27 /-3$ & $125 / 9 / 0$ & $\mathrm{Nr}$ \\
\hline $\begin{array}{l}\text { Features at } \\
\text { presentation }\end{array}$ & $\begin{array}{l}\text { Gluteal fistula, muscle } \\
\text { weakness, joint pain }\end{array}$ & Joint pain & Joint pain & $\begin{array}{c}\text { Muscle weakness and } \\
\text { leg pain }\end{array}$ & Glaucoma \\
\hline Acro-osteolysis & Yes & Yes & Yes & Yes & Yes \\
\hline $\begin{array}{l}\text { Joint } \\
\text { subluxation }\end{array}$ & Yes & Yes & Yes & No & Yes \\
\hline Tendon rupture & No & No & No & No & $\begin{array}{c}\text { Yes: quadriceps, } \\
\text { bilateral, at age } 34 \text { and } \\
35 \text { years }\end{array}$ \\
\hline $\begin{array}{l}\text { Peri-articular } \\
\text { calcifications }\end{array}$ & Yes & Yes & Yes & No & No \\
\hline $\begin{array}{l}\text { Abnormal } \\
\text { dentition }\end{array}$ & $\begin{array}{c}\text { Yes: delayed eruption of } \\
\text { first and secondary } \\
\text { dentition }\end{array}$ & $\begin{array}{c}\text { Yes: loss of teeth in } \\
\text { adolescence leading to } \\
\text { use of prosthesis }\end{array}$ & $\begin{array}{l}\text { Yes: loss of teeth in } \\
\text { adolescence leading to } \\
\text { use of prosthesis }\end{array}$ & $\begin{array}{l}\text { Delayed eruption of } \\
\text { secondary dentition }\end{array}$ & $\begin{array}{l}\text { Yes: delayed tooth } \\
\text { eruption and early loss of } \\
\text { secondary dentition with } \\
\text { resorption of dental roots }\end{array}$ \\
\hline $\begin{array}{l}\text { Glaucoma (age } \\
\text { at diagnosis in } \\
\text { years) }\end{array}$ & No & No & No & No & Yes (11) \\
\hline $\begin{array}{l}\text { Aortic / cardiac } \\
\text { valve } \\
\text { calcification }\end{array}$ & No & Yes & Yes & No & NA \\
\hline Cardiac status & $\begin{array}{l}\text { Hypertension, concentric } \\
\text { LVH, mild left atrial and } \\
\text { aortic root dilation with }\end{array}$ & $\begin{array}{l}\text { Hypertension, LVH, } \\
\text { aortic valve stenosis }\end{array}$ & Aortic valve calcification & No & NA \\
\hline
\end{tabular}




\section{MDA5 Jaccoud}

\begin{tabular}{|c|c|c|c|c|c|}
\hline & aortic valve insufficiency & & & & \\
\hline $\begin{array}{l}\text { Psoriaform rash } \\
\text { (age at onset in } \\
\text { years) }\end{array}$ & Yes (13) & No & Yes (21) & No & Yes (early adulthood) \\
\hline $\begin{array}{l}\text { Multiple } \\
\text { lentigines }\end{array}$ & Yes & Yes & No & No & Yes \\
\hline $\begin{array}{l}\text { Basal ganglia } \\
\text { calcification }\end{array}$ & Yes & Yes & Yes & No cerebral imaging & No cerebral imaging \\
\hline $\begin{array}{l}\text { High hair line / } \\
\text { broad forehead }\end{array}$ & Yes & Yes & Yes & Yes & Yes \\
\hline $\begin{array}{l}\text { Prominent } \\
\text { muscle } \\
\text { weakness }\end{array}$ & $\begin{array}{c}\text { Yes, as infant with } \\
\text { myopathic changes on } \\
\text { muscle biopsy }\end{array}$ & No & No & As an infant & No \\
\hline $\begin{array}{l}\text { Interferon score } \\
\text { (age in } \\
\text { years)(normal < } \\
2.466 \text { ) }\end{array}$ & $29(18)$ & $15.1(45)$ & $16.8(27)$ & $14(9)$ & $18.8(47)$ \\
\hline $\begin{array}{l}\text { Inflammatory } \\
\text { markers / } \\
\text { autoantibodies }\end{array}$ & $\begin{array}{c}\text { ESR and CRP normal; } \\
\text { autoantibodies (ANA, } \\
\text { anti-dsDNA) and } \\
\text { rheumatoid factor } \\
\text { negative; HLAB27 } \\
\text { positivity; C3 and C4 } \\
\text { normal }\end{array}$ & $\begin{array}{c}\text { ESR and CRP normal; } \\
\text { autoantibodies (ANA, } \\
\text { anti-dsDNA, SM/RNP, } \\
\text { Scl 70) and rheumatoid } \\
\text { factor negative; C3 and } \\
\text { C4 normal }\end{array}$ & $\mathrm{Nr}$ & $\begin{array}{c}\text { ESR and CRP normal; } \\
\text { mildly elevated anti-ds } \\
\text { DNA antibodies on one } \\
\text { occasion; ANA, anti- } \\
\text { MDA5 and anti-CCP } \\
\text { antibodies negative; } \\
\text { rheumatoid factor } \\
\text { negative; monocyte } \\
\text { CD169/Siglec1 } \\
\text { expression increased; } \\
\text { C3 slightly reduced, C4 } \\
\text { normal }\end{array}$ & $\begin{array}{l}\text { ESR and CRP normal; } \\
\text { rheumatoid factor } \\
\text { increased; elevated } \\
\text { ANA, anti-CCP, anti-SS- } \\
\text { A/anti-SS-Ro and anti- } \\
\text { angiotensin II type 1 } \\
\text { antibodies; anti-ds DNA } \\
\text { antibodies normal; } \\
\text { monocyte } \\
\text { CD169/Siglec1 } \\
\text { expression increased; } \\
\text { C3 and C4 normal }\end{array}$ \\
\hline
\end{tabular}

$\mathrm{NR}=$ Not recorded; $\mathrm{NA}=$ Not assessed; $\mathrm{LVH}=$ Left ventricular hypertrophy; $\mathrm{ESR}=$ Erythrocyte sedimentation rate; $\mathrm{CRP}=\mathrm{C}$ reactive protein

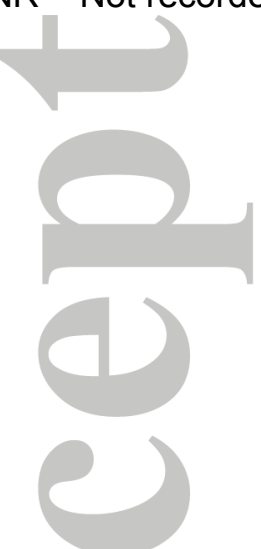


MDA5 Jaccoud

\section{Figure legends}

Figure 1. Radiological and clinical features observed in F1938_P1. X-rays of hands $(A)$, right foot $(B)$ and upper limbs $(C, D)$ demonstrating subluxations (broken arrows) with well preserved joint spaces and articular surfaces, and dense calcification of tendon insertions at the elbows (solid arrows) which was not palpable. Camptodactyly, subluxation and plantar collapse are obvious on clinical observation of the hands (E) and feet (F) at age 18 years. Note also the pigmentary abnormalities seen here on the hands. CT scan of the brain $(G)$ at age 18 years demonstrating dense calcification of the basal ganglia (in the absence of any neurological signs or symptoms).

Figure 2. Radiological and clinical features observed in F1938_P2. X-rays of hands $(A)$, knee (B), left femur and hip (C) and left foot (D) demonstrating significant deformities and ectopic calcification at the sites of tendon insertion (solid arrows). Xray of the jaw (E) shows a complete absence of teeth. Musculoskeletal deformities of the hands $(F)$ and feet $(G)$ at age 45 years are obvious. Transverse CT of the chest $(\mathrm{H})$ demonstrating dense ectopic calcification of the aortic valve.

Figure 3. Radiological features observed in F1972_P1 and F1972_P2. X-rays of the left hand of F1972_P1 (A), and of the hands $(B, C)$ and feet $(D, E)$ of her father F1972_P2. In A, at age eight years there are no major radiological changes beyond slight osteopenia, whilst bilateral subluxation of the thumbs and hallux deformity of

the large toes are present in her father at age 47 years. Note also a suggestion of acro-osteolysis of the phalanges in B and C. 
MDA5 Jaccoud

\section{Figure 4. Cartoon of MDA5 protein and disease-associated mutations.}

Schematic illustrating the protein domains and their amino acid boundaries within the 1025 amino acid protein MDA5. CARD denotes caspase activation recruitment domain. Hel denotes helicase domains, where Hel1 and Hel2 are the two conserved core helicase domains, and Hel2i is an insertion domain that is conserved in the RIG-I like helicase family. $\mathrm{P}$ denotes pincer or bridge region which connects Hel2 to the C-terminal domain (CTD) involved in binding double stranded RNA. Mutations above the line have been recorded in patients with a Singleton Merton-syndrome phenotype. Mutations below the line have been described in patients with a neurological phenotype. Numbers in brackets are numbers of families with each mutation in the literature. * Denotes variant identified in 3 members of the same family, two with a neurological phenotype and one with a Singleton Merton-syndrome phenotype(3). If Denotes variant identified in 3 families segregating a Singleton Merton-syndrome phenotype(7), an individual with predominant neurological involvement more consistent with Aicardi-Goutières syndrome(13), and a further family including a patient with features of Singleton-Merton syndrome, spastic paraparesis and systemic lupus erythematosus(12).

\section{Figure 5. Data relating to type I interferon status in families F1938 and F1972.}

(A) Expression of six interferon stimulated genes (ISGs). Interferon scores, given in brackets followed by decimalised age, of greater than 2.466 are considered abnormal. (B) IFIH1 mutants activate the interferon signaling pathway more efficiently than wild-type IFIH1. (a) Interferon beta (IFN-b) reporter activity (mean \pm s.d., $n=3$ biological replicates) of Flag-tagged wild-type and mutant IFIH1 with and 
MDA5 Jaccoud

without stimulation with poly(l:C) or 162-bp dsRNA in HEK 293T cells. Error bars represent the standard deviation of three independent experiments.

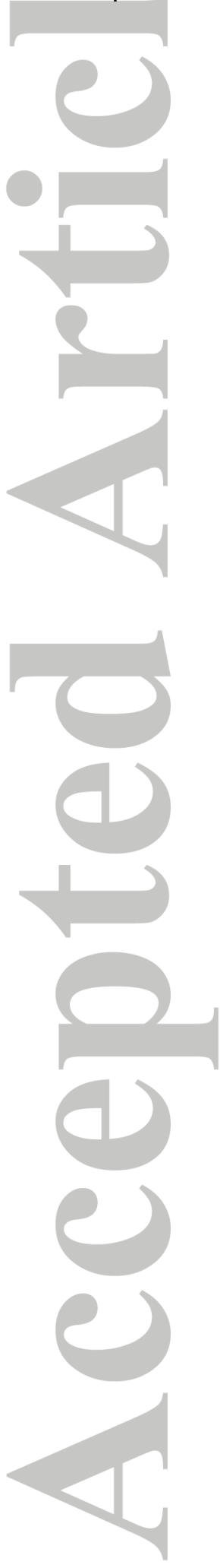

John Wiley \& Sons 


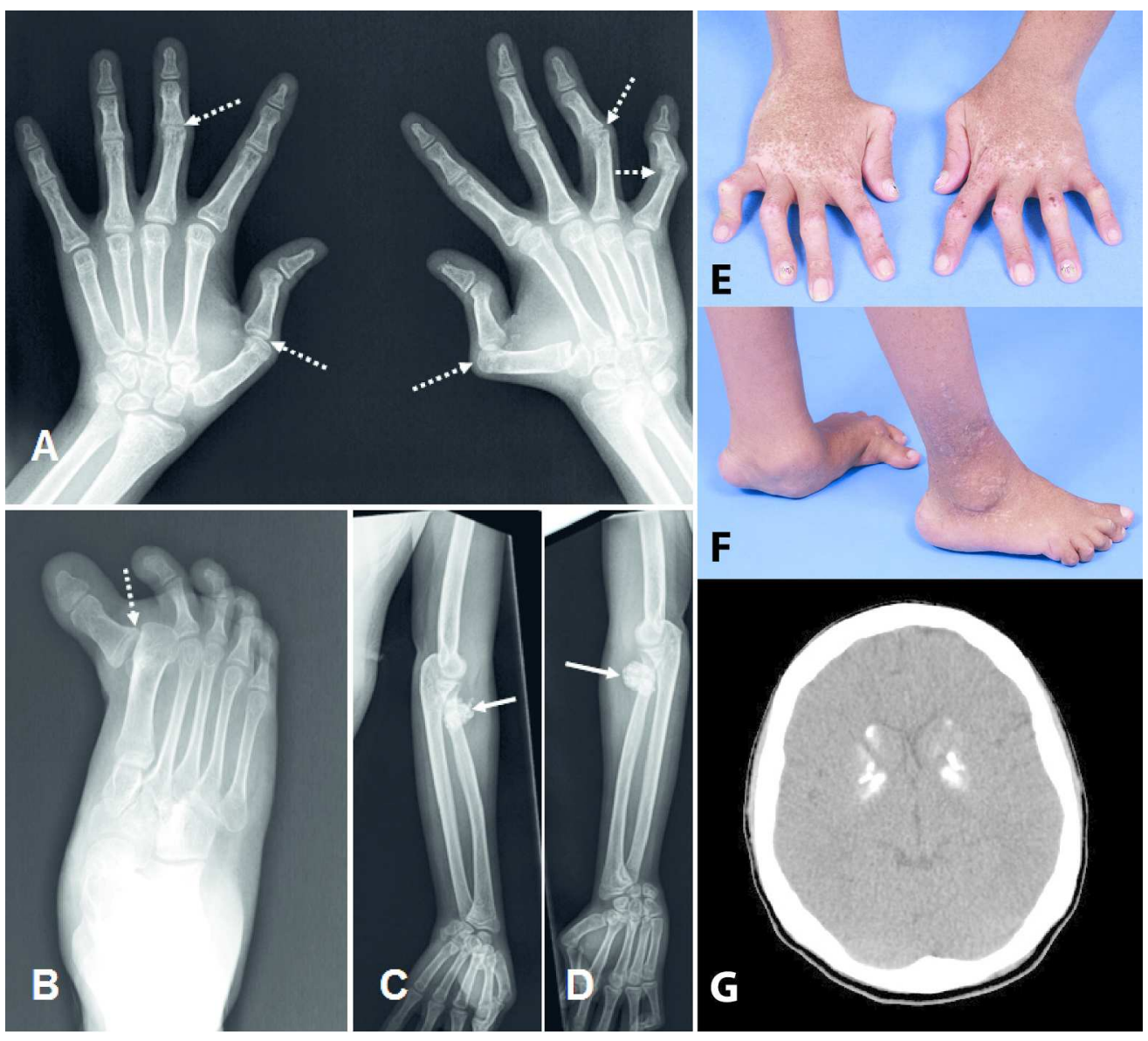

Figure 1. Radiological and clinical features observed in F1938_P1 $203 \times 182 \mathrm{~mm}(300 \times 300 \mathrm{DPI})$

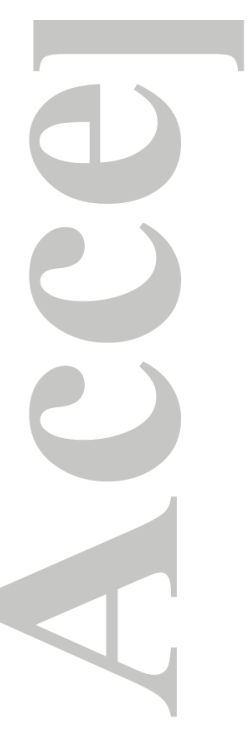

John Wiley \& Sons

This article is protected by copyright. All rights reserved. 


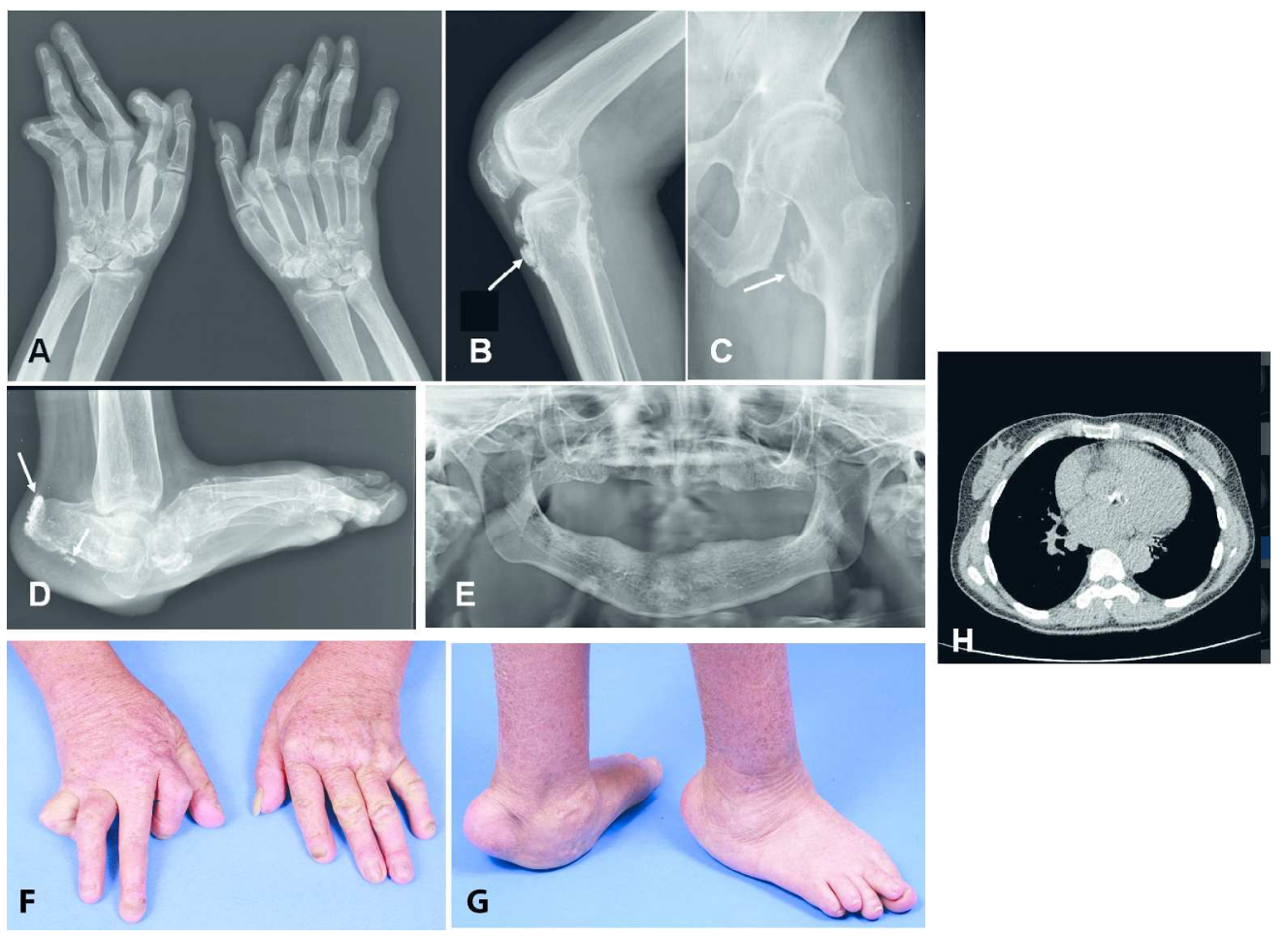

Figure 2. Radiological and clinical features observed in F1938_P2

$274 \times 200 \mathrm{~mm}(300 \times 300 \mathrm{DPI})$ 


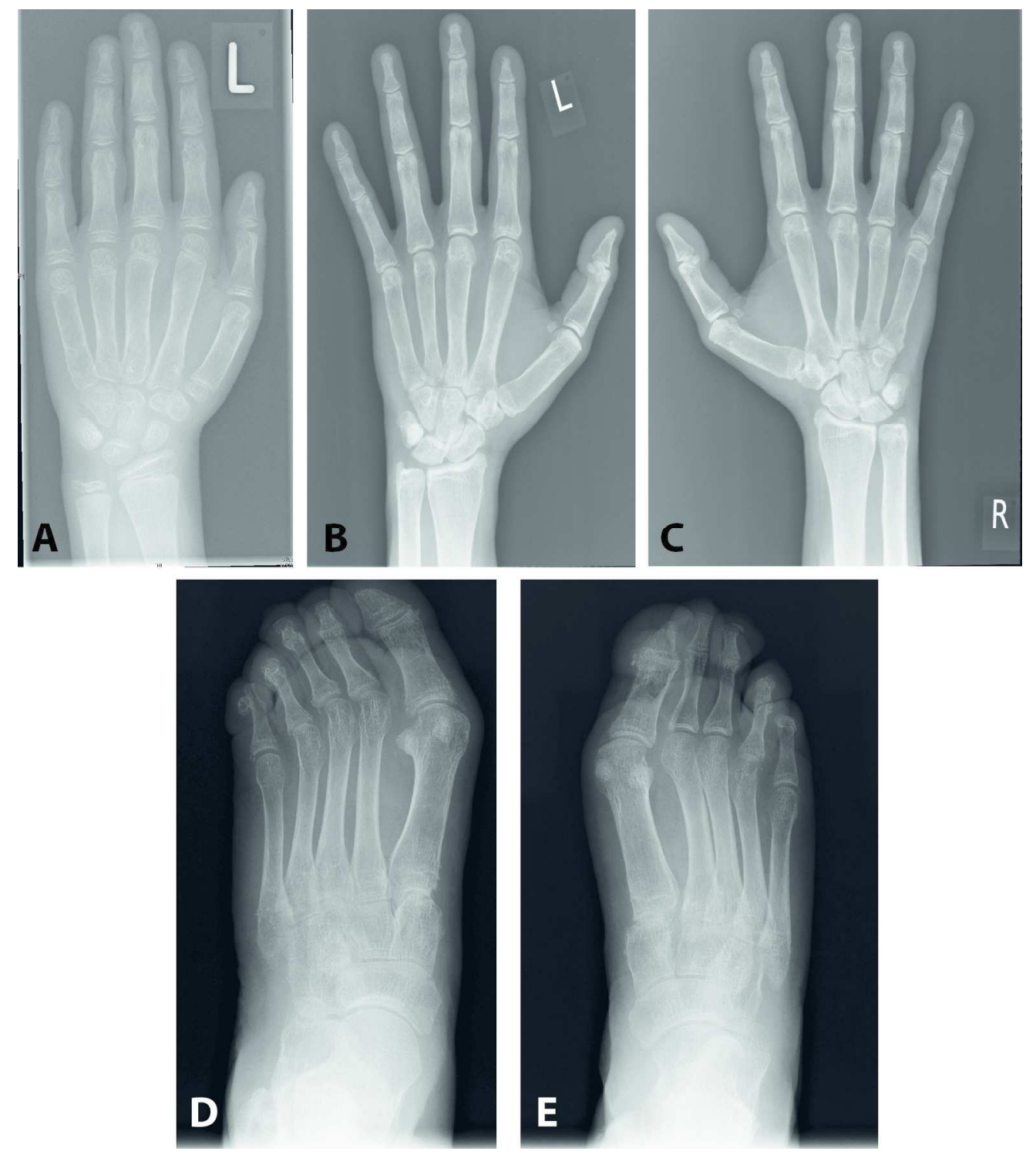

Figure 3. Radiological features observed in F1972_P1 and F1972_P2 $174 \times 197 \mathrm{~mm}$ ( $300 \times 300$ DPI)

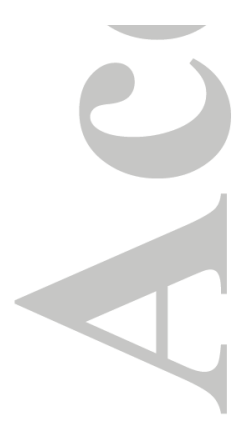

John Wiley \& Sons

This article is protected by copyright. All rights reserved. 


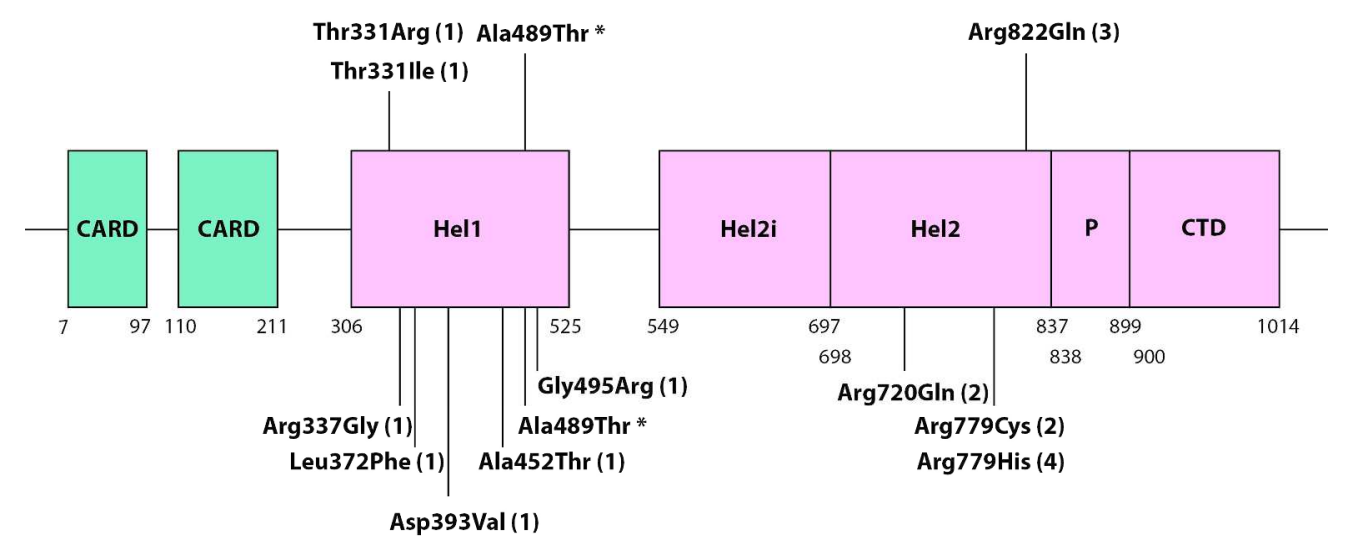

Figure 4. Cartoon of MDA5 protein and disease-associated mutations.

$262 \times 104 \mathrm{~mm}(300 \times 300 \mathrm{DPI})$ 


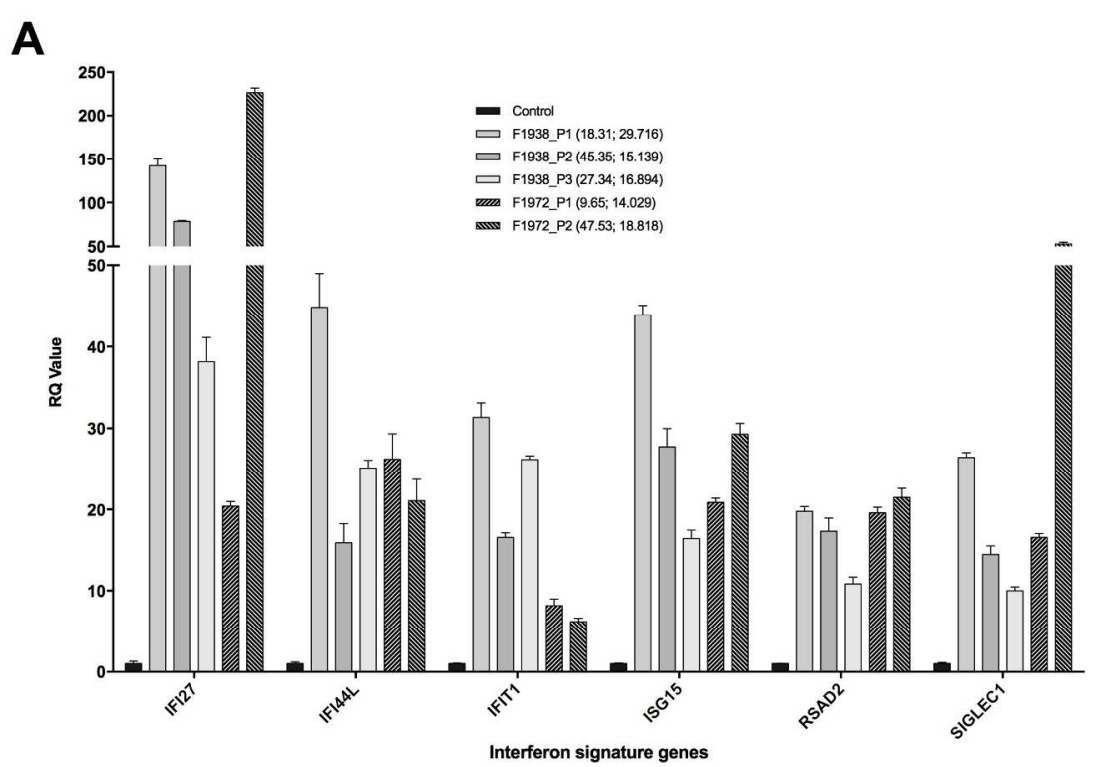

B

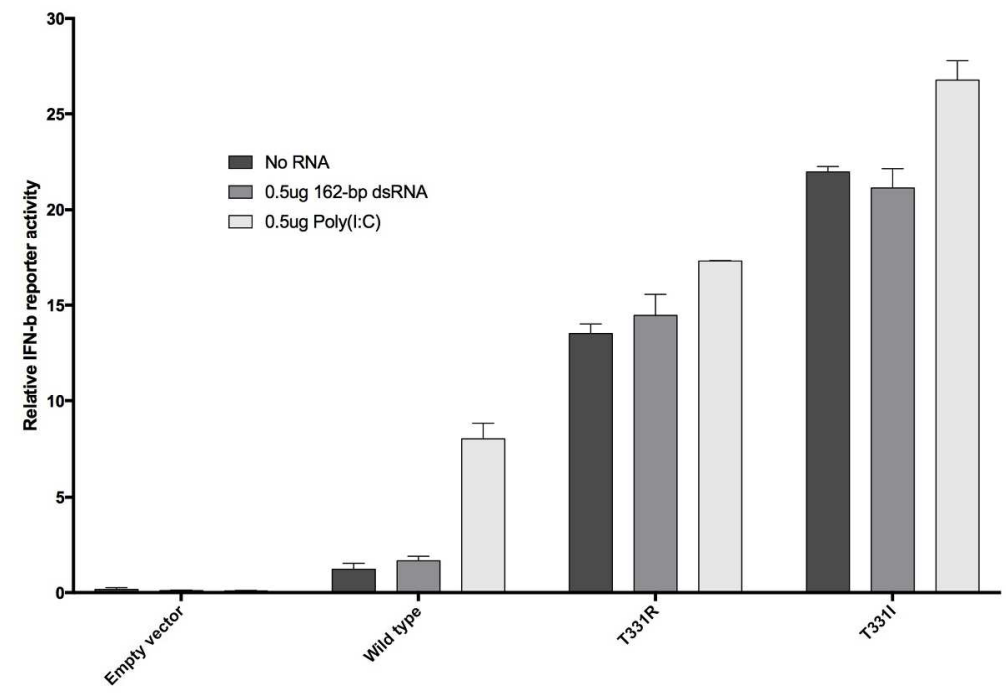

Figure 5. Data relating to type I interferon status in families F1938 and F1972. $170 \times 241 \mathrm{~mm}(300 \times 300 \mathrm{DPI})$

\section{John Wiley \& Sons}

This article is protected by copyright. All rights reserved. 